\title{
DISCURSO PROFERIDO PELA PROF. DRA. ADA PELLEGRINI GRINOVER À TURMA DE 1957 (QUADRAGÉSIMO ANO DE FORMATURA)
}

O esquema do discurso ficou pronto. Tem tudo para ser um bom discurso: começo, meio e fim; passado, presente e, porquê não?, futuro. A lembrança dos cinco anos que transcorremos juntos, aqueles que realmente moldaram nossas personalidades. A saída da escola para as intempéries da vida. Vida profissional, vida política, vida pessoal. O reencontro, após quarenta anos, para o balanço geral. $\mathrm{O}$ sucesso e o fracasso. As vitórias e as frustrações. Os que fizeram a vida e os que viram a vida passar. A lembrança dos que se foram ou que se perderam pelas estradas do mundo. E uma mensagem final, madura, equilibrada, serena, adequada a quem já passou dos sessenta.

Mas estou cansada. O dia foi extremamente longo e insuportavelmente quente. Aulas, reuniões, o telefone que não parou, o fax com suas mensagens extemporâneas, aquele parecer para terminar. Vou relaxar um pouco antes de sentar no computador. Abro portas e janelas, ligo o rádio, recosto-me na poltrona mais confortável, fecho os olhos. Um pouquinho só, que mal vai fazer?

A Scala FM está transmitindo a Heróica de Beethoven. A sinfonia já está no meio, posso ouvi-la até o fim. E deixo-me enlevar pela música.

São os acordes mais tocados à época que me transportam ao século XIX, ou entrei mesmo no túnel do tempo? Silêncio, vamos fazer silêncio. Há damas e cavalheiros, trajados com roupas adequadas a uma grande recepção vespertina, entrando pelo adro do Convento de São Francisco. Por ali normalmente transitam os frades, mas hoje, $1^{\circ}$ de março de 1828 , só se vêem altas autoridades e numerosos convidados. Dirigem-se à sala n. 2, a mais vasta do andar térreo, mesmo assim pequena para o grande público que vai chegando. As roupas de festa contrastam com a simplicidade do velho mosteiro, de paredes de taipa, mas as pessoas não se importam. Conversam e dão risadas, excitadas pela novidade. Silêncio, por favor. Com pompa e circunstância, o professor José Maria de Avelar Brotero, primeiro e único lente dos novos Cursos Jurídicos, começa a proferir a aula inaugural. Todos aplaudem freneticamente, mas ninguém entendeu absolutamente nada. Claro, houve resistêricias para instalar o curso em São Paulo, em face da pobreza da cidade, da dificuldade de acesso ao planalto e do linguajar caipira do povo. O Tietê bem pode valer o Mondego do outro hemisfério como disse o deputado Carvalho e Melo, 
depois Visconde da Cachoeira -, mas por ora a população, mesmo quando abastada, é bastante inculta. Até para os candidatos à matrícula inicial será necessário criar o Curso Anexo à Faculdade de Direito, inicialmente ministrado no Colégio dos Jesuítas e, mais tarde, num velho edifício do Largo de São Francisco, chamado pelos estudantes de "curral dos bichos"

Os estudantes, ah, os estudantes. Afinal, o acesso ao planalto não é tão difícil assim, se tantos vieram de tão longe: até mesmo de Coimbra chegaram, expulsos por terem participado de movimentos liberais contra D. Miguel, ou da própria Olinda, pois o curso pode ser feito em parte lá e em parte aqui. É o caso de Teixeira de Freitas, que vai bacharelar-se em 1836. As salas ficam ao redor do pátio, conhecido, como em Coimbra, como "Os Gerais", por ser esse o local em que todos se reúnem. Até porque o corpo docente, que aos poucos vai completando-se com novas nomeações, brilha pela ausência e o pátio, onde os moços se encontram para debater idéias, declamar poesias ou tramar conspirações, é a verdadeira alma da Academia.

Esperem, Beethoven acabou. Que é isso agora? Parece Verdi, sim a Aída de Verdi. É a Marcha Triunfal, não é? Muito apropriada aos anos sessenta (do século XIX, é claro) e às estrepolias dos estudantes. São Paulo já foi tomada pelas Repúblicas, algumas perto da Faculdade, outras além dos Piques, na Rua da Palha ou no Campo dos Curros, outras ainda no Largo da Glória. Há a república dos sulistas, dos campineiros, dos mineiros, os mais numerosos. E os estudantes participam de tudo: circos de cavalinhos, festas religiosas, procissões, caçadas e torneios, banhos de rio e passeios de canoas nas águas límpidas do Tietê e do Tamanduateí, sempre alegres e irreverentes, animando e escandalizando, sacudindo a cidade provinciana que se modifica sob os olhos

\section{"dos moços da Academia, na noite tão fria, cantando canções"}

Mas não é só isso: a Faculdade vive momentos de grande efervescência, em torno dos ideais abolicionista e republicano, tornando-se o celeiro de grandes políticos: Prudente de Moraes, Campos Salles, Bernardino de Campos, Rangel Pestana e José Maria da Silva Paranhos, o Barão de Rio Branco.

Onde estou agora? Na Casa da Ópera, no Teatro São José ou no Teatro Batuira? E de quem é a música? Escutem, é o Guarani de Carlos Gomes. Já são os anos setenta, corre a Festa da Chave. Poucos entendem seu significado, pois 
Júlio Frank já faleceu e as sociedades secretas, de cunho liberal e filantrópico, ficaram para trás. Mas o corpo do fundador da "Burschenschaft" está enterrado num dos pátios das Arcadas e a Festa da Chave, que se repete todo final do ano, ainda marca a passagem da chefia da Bucha, das mãos de um formado para as de um quartanista. Também se foi a época dos poetas Álvares de Azevedo, Fagundes Varela e Castro Alves. Mas estão aqui Rui Barbosa e Joaquim Nabuco, além dos futuros presidentes da República, Rodrigues Alves e Afonso Pena. E, em plena Faculdade, está instalada uma mostra, a Exposição Provincial, com os produtos a serem enviados à Exposição Internacional de Filadélfia.

Cuidado, algo grave está acontecendo. A música calou-se. O toque de rebate de todas as igrejas anuncia o desastre. É a madrugada de 16 de fevereiro de 1880 e um incêndio pavoroso destruiu a capela-mor da Igreja de São Francisco e a sala do arquivo da Faculdade de Direito afetando substancialmente o velho edifício. Panos embebidos em querosene atestam tratar-se de incêndio doloso, as suspeitas apontam para alguns alunos descontentes com as notas, mas a comissão encarregada de apurar os fatos não chega a resultado algum. Já naquele tempo?

O prédio passa por uma grande reforma, executada pelo engenheiro Luís Pucci. A singela fachada é substituída por outra, em estilo renascença. O Salão Nobre é ricamente decorado por Vilalonga. A Faculdade passa a ter entrada independente, com três portas encimadas por placas de mármore com os nomes dos grandes poetas da Academia, abrindo-se para o largo. $\mathrm{O}$ vetusto convento começa a ficar desfigurado. Já naquele tempo.

Agora é Ravel quem toca. É o fim do século. Maria Augusta Saraiva acaba de matricular-se no curso de Direito. É a primeira mulher que se formará advogada. Concentrem-se, atençã̀o: é o ano de 1903 e acaba de ser fundado o Centro Acadêmico XI de Agosto, a mais antiga associação de estudantes do país. A sessão de instalação, a primeira reunião noturna da Faculdade, é iluminada por uma ligação elétrica provisória. Toma alento o trote, infligido com uma série de sofrimentos e humilhações pelos "calouros enfeitados" aos ingressantes, até estes atingirem a suspirada alforria, que virá no dia da peruada, com carros alegóricos desfilando pelo centro da cidade e os calouros declamando e fazendo discursos, sob vaias e insultos.

"Nem tudo que reluz é ouro, nem todo sopapo é murro, nem todo burro é calouro, mas todo calouro é burro" 
Já naquele tempo?

Ao som de Debussy, entro nas primeiras décadas do novo século: as grandes atrações são as temporadas líricas e de operetas, onde os estudantes entram de "carona", agradecendo o convite com calorosas saudações à prima-dona. É o prenúncio da "pindura" reservada depois ao dia 11 de agosto. Começa também o cinema mudo e o Parque Antártica torna-se um dos pontos altos das comemorações acadêmicas, com jogos de futebol entre universitários: a Light põe seus bondes à disposição dos atletas e a Antárctica fornece chope à vontade. Já naquele tempo.

O tempo vai passando. Não há mais música. São vozes que ecoam agora, é um comício de protesto contra a morte de João Pessoa. A Faculdade está interditada pelo Governo e os jovens criam o Território Livre do Largo de São Francisco, onde debatem os grandes assuntos nacionais. Os mesmos que aplaudiram a chegada de Getúlio Vargas a São Paulo, em 1930, traídos em seus ideais, pegam em armas em 1932. A revolta contra a perda da autonomia estadual, o desejo de ver restabelecido o regime constitucional, ós trágicos acontecimentos do ano impelem os estudantes a transformarem as Arcadas em trincheira, e daqui partem grupos de voluntários, professores e alunos, formando os batalhões "14 de julho" "Piratininga" e "Ibrahim Nobre".

"Quando se sente bater

no peito heróica pancada,

deixa-se a folha dobrada

enquanto se vai morrer"

E sete não voltam aos bancos acadêmicos. Seus nomes ficam gravados no Monumento aos Heróis de 32, no pátio.

A música recomeça, mas não consigo identificá-la. Vários temas sucedem-se, enquanto diversas figuras vão se formando e desmanchando, como num caleidoscópio. A Turma do Esqueleto, que favoreceu a fuga de um casal de ossadas da sala de Medicina Legal, com o esqueleto-varão aparecendo pendurado no Viaduto do Chá. A demolição do casarão de taipa e a reconstrução do edifício, no estilo bastante discutido "renascimento-barroco-jesuítico" A transferência da Faculdade de Direito da esfera federal para o governo de São Paulo, com o núcleo inicial da USP..E a guerra, com os estudantes exigindo a luta do Brasil contra o Eixo. O Baile das Américas de 1943, com as demonstrações contra Vargas, a prisão de professores e alunos e a invasão da sede do Centro Acadêmico pela polícia. A Passeata do 
Silêncio, com os participantes usando uma mordaça, a simbolizar a censura imposta pelo Estado Novo. E o fim da guerra, a derrubada do regime ditatorial e a democratização do país. As figuras sucedem-se, animam-se, desaparecem. Faz-se novamente o silêncio. Há uma longa pausa. Começo a mexer-me na poltrona, estou despertando.

Mas o rádio não deixa. Imaginem, são os anos dourados! Blue Moon, Stranger in Paradise, Beguin the beguine. Quem entra dançando pelos portões da Faculdade? Rapazes de terno e gravata, moças de cabelinho curto e saia rodada, casais enlaçados como num musical dos anos cincoenta. Mas quem são eles, afinal? Vejam, somos nós! É o Pedrinho Furlan que avança com a Ivete Girardi, Anna Maria nos braços de Jean Pierre, Ayrton rodopiando com Maria Abadia, Vicente e Maria Lúcia Pimentel, Ronaldo Porto Macedo e Lenita - que não desgruda dele. E logo atrás um grupo grande, rindo e brincando: Myrthes, Beth (a morena), Raphael e Flávio Novaes; Jamil Achôa, Nilce e Julieta, Doracy e Iracy; Modesto Carvalhosa e Claudio Regina; Neide Faleiros, Edith, Inacita e Sônia; Miguel Aldrovando Haith, Antonietta Losso e Lúcia Valle; Theodoro, Júlio César Vizeu e Beth (a loira); Adel Auada e Luiza Ribeiro; Ida Maria, Antonini, Adalberto; Graciosa, Hermínio, Laís Colin e João Lopes Guimarães; Ennio Pesce e Romolo Massari; Hamilton e Nelson Altemani. E Mauro, que sempre acompanha a turma. São muitos mais, mas não dá tempo de nomeá-los todos. Já estão entrando na sala João Mendes Jr., recompõemse, sentam, aguardam os professores. O bedel o Bottini, naturalmente avisa que os Mestres estão chegando e lá vêm eles, Goffredo Silva Telles, Ataliba Nogueira, Alexandre Correia, Cândido Motta Filho, Luís Eulálio de Bueno Vidigal, Lino. Leme, Honório Monteiro, Alvino Lima, Braz Arruda e Marotta Rangel, Miguel Reale, Soares de Mello, Cesarino, Gama e Silva, e mais outros que não consigo indicar porque, enquanto todos se levantam, a cena desaparece.

E eis que lá estão os jovens de novo, agora ao som de Glenn Miller, um grupo de rapazes e moças, na Livraria Saraiva, comprando livros em módicas prestações nem sempre pagas. Outros estacionam na pastelaria do Largo, fazendo uma boquinha. As mais elegantes namoram as vitrines da Sloper e as mais sofisticadas tomam chá - a essa hora? na Barão de Itapetininga. Agora é de noite, estão todos numa festa, Guilherme Quintanilha de Almeida repreende escandalizado Ada Pellegrini e o namorado (um estudante de arquitetura, imagine!) que se beijam em público. Onde já se viu tamanha falta de respeito? Lucio parte para cima de 
Guilherme, a turma do deixa-disso intervém, um bolero toca, vamos tomar uma cuba-libre?

Renê vende suas apostilas "sem responsabilidade da ilustre cátedra" mas podem confiar, toma nota de tudo, até dos espirros do professor. Deveria saber tudinho, não deveria? mas o primeiro da classe é Eduardo Henry. A turma da JUC Luiz Carlos Bresser, Maneco, Mário Masagão, Fernão Bracher, Milliet, D'Andréa -, passa os intervalos encostada nos arcos do pátio, mantendo à devida distância os comuns mortais e não é à toa que as amigas de Ivette Senise vibram todas as vezes e não são poucas - que ela rompe com o Manoel. A turma tem duas misses Irma, Miss Mato Grosso e Lilian Batori, Miss Grécia mas as pernas mais lindas são de Alzira Helena. Ondina Bergamo gosta de saias justas, mas tão justas que obriga a costureira a colocar um ziper de cada lado para que a peça marque mais as cadeiras. Domiraide de Lucca descobriu os encantos da base e a usa em profusão, de modo a pôr em relevo os lindos olhos azuis mas também o pescoço alvo, em contraste com a cor viva da tez. Salomão Esper Salomão discorre com proficiência a respeito da Última Ceia e do fato de que Jesus não prometeu renovar o milagre na missa, como pretendem os católicos. Ada, embora considerada por Maneco "a italianinha metida a gênio". passa boa parte das aulas de Economia Política jogando guerra naval com Murilo Tricca e Fleury. Dulce Tocci, que engravidou logo após o casamento, tenta prestar exames antecipados, mas o regulamento não permite. E há também as desavenças: Norma Noschese Zumsteg briga de morte com Hamilton Caetano de Mello e meia Comissão de Formatura, ao que consta por terem esvaziado garrafões de vinho na fonte de sua casa na Rua Augusta, matando todos os peixinhos vermelhos. E a turma do Paulo Gerab, constantemente ébria, despedaça e atira na cara do pessoal a torta que Myrthes levou à Sala do Estudante para festejar seu aniversário.

As moças freqüentam o Departamento Feminino, pois o Centro Acadêmico é ainda domínio dos homens, até que um dia Alzira Helena encabeça um grupo de garotas que invade o restaurante. Os moços protestam, ameaçam tirar a roupa, as meninas os enfrentam e o Departamento Feminino acaba com o tempo tornando-se uma excrescência, salvo pelo que toca ao esporte, coordenado por Pedrinho Furlan. Somos ainda nós o dez por cento de mulheres da turma - que nos recusamos a sair das aulas de Medicina Legal, quando Almeida Júnior adverte que entrará na matéria de sexologia e que as moças que se sentirem incomodadas poderão retirar-se. Mesmo assim, provoca escândalo a atitude dos "cafajestes" que 
resolvem jogar preservativos (que ainda não se chamam camisinhas) cheios de água na cabeça da veterana Júlia, a moça mais liberada da Escola que se orgulha de conviver com um rapaz, a quem chama atrevidamente de "meu amante". O sempre recatado Guilherme Quintanilha observa que "se fosse com minha irmã, não saberia sequer do que se trata", mas as meninas fazem-se de sabidas, não querendo passar por ignorantes. E ninguém leva a sério - nem mesmo o Guilherme as descrições de cenas pseudo-eróticas do professor Soares de Mello, que se deleita, durante um semestre inteiro, falando sobre crimes contra os costumes.

O corpo docente é uma história em vários capítulos. Não se sabe como a turma, praticamente sem aulas de Constitucional, poderá gerar um Dalmo Dallari, um Manoel Gonçalves Ferreira Filho e um José Afonso da Silva. O professor Gama e Silva narra episódios intrincadíssimos, em que a mulher, de nacionalidade australiana, casa com um irlandês na Argentina, tendo os dois como primeiro domicílio conjugal o Congo Belga, e promete revelar o regime de bens, à luz do Código Bustamante, na próxima aula, deixando todos em suspense pelo resto da vida. O amabilíssimo Alvino Lima acha tão complicado o Direito das Sucessões, que se atrapalha com as explicações sobre os mistérios da herança por estirpe e por cabeça, que a turma conseguiu decifrar imediatamente. Mestre Canuto pouco fala de Processo Penal, mas discorre com tanta simpatia sobre samba e cinema, que as aulas são extremamente concorridas. Outros docentes são magistrais: Esther de Figueiredo Ferraz, em sua passagem fugaz, encanta as moças e faz Ivette Senise deslumbrar-se com o Direito Penal. Cesarino Júnior - com perdão dos que não conseguirão formarse senão quando se aposentar - consegue o milagre, impensado à época, de complementar as aulas teóricas com aulas práticas. Vidigal põe em campo todo um time de italianos - com o ataque formado por A. Rocco, Chiovenda, Calamandrei e Carnelutti e durante um semestre afirma coisas incompreensíveis e insensatas, até que a turma, como que fulgurada ao longo da estrada de Damasco, recebe a revelação e passa a entender e gostar do Processo Civil. Goffredo é empolgante, Miguel Reale, insuperável. E, sobre todos campeia a figura bizarra do sapiente Alexandre Correia, que às vezes chega de bicicleta à Faculdade.

Ouvem-se agora as trovas acadêmicas, incluindo as de novo feitio sobre os docentes da turma. O veterano Lauro é mestre nos desafios, que têm como estribilho "Em Tietê fizeram cadeia nova, Mariazinha coitadinha é criminosa" E os últimos boêmios da Academia, encabeçados por Chico Emygdio, reúnem-se em chopadas e serenatas, entoando o hino de guerra: 


\section{"Vilela, Vilela, \\ vamos fazer revolução, \\ nosso chefe é você Vilela, nossa arma o garrafão"}

Os cinco últimos anos acabaram de passar por trás das pálpebras fechadas. Mais um momento de paciência, por favor: é o dia da formatura, com a Missa na Catedral, as fotos em branco-e-preto, a cerimônia de colação de grau no Salão Nobre, o baile no Clube Pinheiros. A conclusão do curso, as expectativas do futuro, o entusiasmo por novos horizontes. O grande momento de luz. As despedidas, as promessas. É Gerschwin que toca agora. O adeus, a distância, a saudade. Os esporádicos reencontros.

Abro os olhos, levanto-me, desligo o rádio. Só resta uma coisa a fazer: jogar fora o esquema do discurso.

Arcadas, 14 de novembro de 1997. 